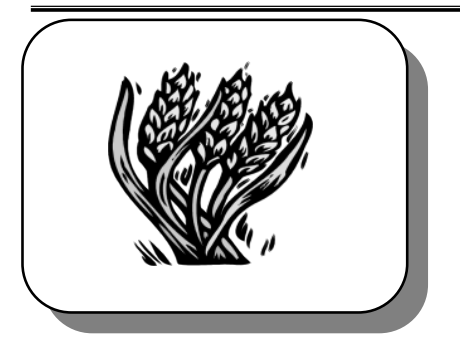

удК 631.43

DOI: 10.36718/1819-4036-2019-12-3-8

\title{
АГРОНОМИЯ
}

Н.Л. Кураченко, О.А. Власенко, О.А. Ульянова, Е.Ю. Казанова, В.В. Казанов, Л.Ф. Казюлин

\section{ТЕМПЕРАТУРНЫЙ РЕЖИМ АГРОЧЕРНОЗЕМОВ ПРИ ВОЗДЕЛЫВАНИИ МАСЛИЧНЫХ КУЛЬТУР В КАНСКОЙ ЛЕСОСТЕПИ*}

\author{
N.L. Kurachenko, O.A. Vlasenko, O.A. Ulyanova, \\ E. Yu. Casanova, V.V. Casanov, L.F. Kazyulin
}

\section{AGROCHERNOZEMS TEMPERATURE REGIME DURING OIL CROPS CULTIVATION IN KANSK FOREST-STEPPE}

Кураченко Н.Л. - д-р биол. наук, профр., зав. каф. почвоведения и агрохимии Красноярского государственного аграрного университета, г. Красноярск.

E-mail: kurachenko@mail.ru

Власенко О.А. - канд. биол. наук, доц. каф. почвоведения и агрохимии Красноярского государственного аграрного университета, г. Красноярск.

E-mail: ovlasenk007@mail.ru

Ульянова О.А. - д-р биол. наук, проф. каф. почвоведения и агрохимии Красноярского государственного аграрного университета, г. Красноярск.

E-mail: kora64@mail.ru

Казанова Е.Ю. - магистрант каф. почвоведения и агрохимии Красноярского государственного аграрного университета, г. Красноярск.

E-mail: ovlasenko07@mail.ru

Казанов В.В. - асп. каф. почвоведения и агрохимии Красноярского государственного аграрного университета, г. Красноярск.

E-mail: ovlasenko07@mail.ru

Казюлин Л.Ф. - студ. 4-го курса Красноярского государственного аграрного университета, г. Красноярск.

E-mail: ovlasenko07@mail.ru
Kurachenko N.L. - Dr. Biol. Sci., Prof., Head, Chair of Soil Science and Agrochemistry, Krasnoyarsk State Agrarian University, Krasnoyarsk.

E-mail: kurachenko@mail.ru

Vlasenko O.A. - Cand. Biol. Sci., Assoc. Prof., Chair of Soil Science and Agrochemistry, Krasnoyarsk State Agrarian University, Krasnoyarsk.

E-mail: ovlasenko07@mail.ru

Ulyanova O.A. - Dr. Biol. Sci., Prof., Chair of Soil Science and Agrochemistry, Krasnoyarsk State Agrarian University, Krasnoyarsk.

E-mail: kora64@mail.ru

Kazanova E.Yu. - Magistrate Student, Chair of Soil Science and Agrochemistry, Krasnoyarsk State Agrarian University, Krasnoyarsk, Krasnoyarsk.

E-mail: ovlasenko07@mail.ru

Kazanov V.V. - Post-Graduate Student, Chair of Soil Science and Agrochemistry, Krasnoyarsk State Agrarian University, Krasnoyarsk, E-mail: ovlasenko07@mail.ru

Kazyulin L.F. - 4-Year Student, Krasnoyarsk State Agrarian University, Krasnoyarsk.

E-mail: ovlasenko07@mail.ru

\footnotetext{
" Исследование выполнено при финансовой поддержке Российского фронда фундаментальных исследований, Правительства Красноярского края, Красноярского краевого фонда науки и обществом с ограниченной ответственностью ООО «ОПХ Солянское», в рамках научного проекта: «Исследование механизмов формирования пула легкоминерализуемого органического вещества в агрогеннопреобразованных почвах Канской лесостепи»
} 
Цель исследования - изучить температурный режим агрочерноземов при воздельвании ярового panca (Brassica napus oleifera annua, Metzd.) и рыжика посевного (Camelina sativa (L.) Crantz) в Канской лесостепи. В структуре почвенного покрова ключевых участков доминируют агрочерноземы глинисто-иллювиальные типичные среднемощные и мощные, по едва заметным микропонижениям встречаются разные виды агрочерноземов глинисто-иллювиальных оподзоленных, на микроповышениях встречаются агрочерноземы криогенно-мицеллярные маломощные. Температурный режим почв в агроценозах масличных культур исследовали термометром «Bayer» в слоях почвы 0-10 и 10-20 см в период с мая по сентябрь на 4 пробных площадях, выделенных в пределах каждого поля. Для сравнительной характеристики температурного режима прилегающего слоя атмосфреры использовались данные Солянской агрометеорологической станции. Интервал измерения температуры почвы - 12-20 дней. Исследованиями установлено, что к началу посева масличньх культур температура 0-20 см слоя почвы не достигла устойчивого перехода через $5^{\circ} \mathrm{C}$, хотя воздух прогрелся до $9^{\circ} \mathrm{C}$. От мая $к$ июню происходило резкое повышение температуры почвы до 13-16 ${ }^{\circ} \mathrm{C}$. В июле поверхность почвы в посевах масличных культур прогревалась до 29-30 ${ }^{\circ} \mathrm{C}$ и превышала температуру воздуха на 5-6 ${ }^{\circ} \mathrm{C}$. В августе агрочерноземы быстро охлаждались до 5-12 ${ }^{\circ} \mathrm{C}$ и отставали на 9-14 ${ }^{\circ} \mathrm{C}$ от температуры воздуха. При отсутствии достоверных отличий в динамике температурного режима почвы в посевах масличных культур обнаружено, что 0-20 см слой агроценоза рыжика в среднем на $2{ }^{\circ} \mathrm{C}$ теплее, чем panса. Также показано, что слой почвы 0-10 см прогревается на 2-3 ${ }^{\circ} \mathrm{C}$ выше, чем 10-20 cM.

Ключевые слова: яровой panc (Brassica napus oleifera annua, Metzd.), рыжик посевной (Camelina sativa (L.) Crantz), температурный режим почв, агрочернозем.

The research purpose was to study the agrochernozems temperature regime during the cultivation of spring rape (Brassica napus oleifera annua, Metzd.) and saffron camelina (Camelina sativa (L.)
Crantz) in Kansk forest-steppe. Clay-illuvial typical medium-powerful and powerful agrocherno-zems dominate in the soil cover structure of key plots; different types of clay-illuvial podzolized agrochernozems are found on micro-lowering; cryogenic-micellar low-power agrocherno-zems are found on microelevations. The soils temperature regime in agrocenoses of oilseeds was studied with the help of thermometer "Bayer" in soil layers of 0-10 and 10-20 cm during the period from May to September on 4 trial plots allocated within each field. The data from the Solyansk agrometeorological station were used for the temperature regime comparative description of adjacent atmosphere. Measuring interval for soil temperature was 12-20 days. The studies showed that by the beginning of sowing oilseeds the 0-20 cm soil layer temperature did not reach stable transition through $5^{\circ} \mathrm{C}$, although the air warmed up to $9^{\circ} \mathrm{C}$. From May to June there was sharp increase in soil temperature up to $13-16{ }^{\circ} \mathrm{C}$. In July the soil surface in oilseed crops warmed up to $29-30^{\circ} \mathrm{C}$ and exceeded air temperature by $5-6{ }^{\circ} \mathrm{C}$. In August, agrochernozems cooled quickly up to $5-12^{\circ} \mathrm{C}$ and lagged $9-14{ }^{\circ} \mathrm{C}$ from air temperature. It was found out that the 0-20 cm camelina agrocenosis layer was on average $2^{\circ} \mathrm{C}$ warmer than rape in significant differences absence in the temperature regime of the soil in oilseed crops dynamics. It is also showed that the soil layer of $0-10 \mathrm{~cm}$ warmed up by $2-3^{\circ} \mathrm{C}$ more than $10-20 \mathrm{~cm}$.

Keywords: spring rape (Brassica napus oleifera annua, Metzd.), Camelina (Camelina sativa (L.) Crantz), soil temperature regime, agrochernozem.

Введение. Температура почвы является одним из ключевых факторов, определяющих фуннционирование и продуктивность экосистем. Многочисленными исследованиями установлено, что именно температура почвы и амплитуда температур между воздухом и почвой на определенных глубинах (а не воздуха) имеют решающее значение в начальный период жизни растений $[1,2]$.

В соответствии с районированием территории России по температурному режиму почв, проведенному В.Н. Димо [3], Канская лесостепь отнесена к Западно-Присаянской почвенной провинции. Суммарная солнечная радиация составляет для этой территории 80-100 ккал/см².год, 
величина радиационного баланса равна 20 ккал/см².год. Эти показатели существенно ниже по сравнению с лесостепной зоной Западно-Сибирской и Предалтайской провинции и свидетельствуют о напряженном температурном режиме черноземов Канской лесостепи.

Климатические условия земледельческой части Красноярского края обусловливают довольно глубокое промерзание черноземов. По классификации температурного режима почв [3], земледельческая часть Красноярского края относится к длительно-сезоннопромерзающему типу. На основании характеристики температурного режима почв в годовом цикле (по среднегодовой температуре почв на глубине 0,2 м) эти почвы относятся к холодному подтипу. Среднегодовая температура почвы в лесостепи $2,7^{\circ} \mathrm{C}$. Небольшая мощность снежного покрова (2040 см) в лесостепях приводит к длительному и глубокому промерзанию почв. На открытых участках до 2,5-3,5 м в течение 9-10 месяцев, а под лесом - до 2 м в продолжение 7-8 месяцев [4]. По данным Л.С. Шугалей [5], мерзлотный период на черноземе выщелоченном Красноярской лесостепи в условиях пашни колебался от 196 до 249 дней. Глубина промерзания достигала 1,5-2,5 м. По данным П.И. Крупкина [6], оттаивание черноземов Канской лесостепи сверху начинается во второй декаде апреля. В третьей декаде этого месяца фиксируются устойчивые положительные температуры на глубине 20 см. В.И. Беляевым и др. [7] доказано, что температурный режим черноземов в разные годы на одном и том же поле неодинаковый и зависит главным образом от погодных условий, технологий обработки почвы и возделываемых культур.

Цель исследования. Изучить температурный режим агрочерноземов при возделывании ярового рапса (Brassica napus oleifera annua, Metzd.) и рыжика посевного (Camelina sativa (L.) Crantz) в Канской лесостепи.

Объекты и методы. Исследование проведено в 2019 году в землепользовании ООО «ОПХ Солянское» в Канской лесостепи КанскоРыбинского геоморфологического округа на двух ключевых участках. Предшествующая культура - горохоовсяная смесь. Агроценоз гибрида ярового рапса Контра КЛ (участок № 1 $56^{\circ} 006^{\prime \prime} \mathrm{N}$ и $95^{\circ} 052^{\prime \prime}$ Е) характеризуется широкоувалистым рельефом со слабовыраженным микрорельефом в виде мелких понижений и по- вышений разной формы, что типично для большей части Канской лесостепи. В структуре почвенного покрова здесь доминируют агрочерноземы глинисто-иллювиальные типичные среднемощные и мощные. По едва заметным микропонижениям встречаются разные виды агрочерноземов глинисто-иллювиальных оподзоленных. Агроценоз ярового рыжика сорта Ужурский (участок № 2 - 56 026" N и 95²43" E) расположен на пологом склоне широкого увала, вытянутого с запада на восток. Данный участок отличается наибольшей комплексностью почвенного покрова и представлен сочетанием агрочерноземов глинисто-иллювиальных типичных разных видов, агрочерноземов глинистоиллювиальных оподзоленных мощных и агрочерноземов криогенно-мицеллярных маломощных, занимающих микроповышения. Температурный режим почв в агроценозах масличных культур исследовали термометром «Вауег» в слоях почвы 0-10 и 10-20 см в период с мая по сентябрь на 4 пробных площадях, выделенных в пределах каждого поля. Для сравнительной характеристики температурного режима прилегающего слоя атмосферы использовались данные Солянской агрометеорологической станции. Интервал измерения температуры почвы - 1220 дней.

Результаты и их обсуждение. Температура почвы влияет не только на ростовые процессы подземной, но и надземной части растений. Повышение температуры верхнего слоя почвы способствует активизации микробиологической деятельности в почве и это обогащает ее необходимыми для растений питательными веществами. Для создания того или иного температурного поля в почве особое значение имеет количество тепла, идущего на подогрев почвы и растительности.

Наблюдения по погодными условиями показали, что начало вегетационного периода 2019 года сопровождалось небольшим количеством осадков и высокой температурой воздуха (табл. 1), однако исследованиями установлено, что к началу посева масличных культур температура 0-20 см слоя не достигла устойчивого перехода через $5^{\circ} \mathrm{C}$ (рис.) и составляла в среднем по полям ключевых участков $4^{\circ} \mathrm{C}$. В этот период почва холоднее воздуха на $5^{\circ} \mathrm{C}$, что связано $\mathrm{c}$ ее промерзанием и медленным оттаиванием. 
Таблица 1

Динамика температуры и осадков за вегетационный сезон 2019 года по данным Солянской агрометеорологической станции

\begin{tabular}{|c|c|c|c|c|c|c|c|c|}
\hline \multirow{3}{*}{ Месяц } & \multicolumn{4}{|c|}{ Температура воздуха, ${ }^{\circ} \mathrm{C}$} & \multicolumn{2}{|c|}{ Осадки } & \multirow{3}{*}{$\begin{array}{c}\text { Средне- } \\
\text { многолетние } \\
\text { показатели } \\
\text { температуры } \\
\text { воздуха, }{ }^{\circ} \mathrm{C} \\
\end{array}$} & \multirow{3}{*}{$\begin{array}{c}\text { Средне- } \\
\text { многолетний } \\
\text { уровень } \\
\text { осадков, } \\
\text { мм } \\
\end{array}$} \\
\hline & \multicolumn{3}{|c|}{ Декада } & \multirow{2}{*}{$\begin{array}{c}\text { Средняя } \\
\text { за } \\
\text { месяц }\end{array}$} & \multirow{2}{*}{$\begin{array}{c}\text { Сумма } \\
\text { за } \\
\text { месяц, } \\
\text { мм }\end{array}$} & \multirow{2}{*}{$\begin{array}{l}\text { Процент } \\
\text { к норме }\end{array}$} & & \\
\hline & 1 & $\|$ & III & & & & & \\
\hline Май & 8,2 & 6,5 & 12,8 & 9,2 & 18,0 & 52,2 & 8,6 & 34,8 \\
\hline Июнь & 15,1 & 18,2 & 19,7 & 17,8 & 111,0 & 201,1 & 17,8 & 55,2 \\
\hline Июль & 20,1 & 18,4 & 17,1 & 18,5 & 58,0 & 67,6 & 18,3 & 85,8 \\
\hline Август & 21,5 & 15,2 & 15,9 & 17,4 & 55,0 & 84,9 & 15,9 & 64,8 \\
\hline Сентябрь & 11,2 & 8,9 & 9,6 & 9,9 & 52,0 & 109,7 & 8,4 & 47,4 \\
\hline
\end{tabular}

Температурное поле пахотных почв, формирующееся в комплексном почвенном покрове, изменялось в небольшой степени (Cv =10-19\%). Агрочерноземы ключевого участка № 1 перед посевом рапса характеризовались температурой, варьирующей на глубине $0-20 \mathrm{~cm}$, от 2 до $4{ }^{\circ} \mathrm{C}$. Склоновый участок № 2 отличался лучшей прогреваемостью ( $p=0,0001)$. При небольшом размахе колебаний температура пахотного слоя агрочерноземов варьировала от 4 до $6{ }^{\circ} \mathrm{C}$. Возникновение и развитие пространственных неоднородностей в температурном режиме почвенного покрова, по мнению Н.А. Шапориной и др. [8], обусловлено пространственной неоднородностью свойств почв, с одной стороны, и метеорологическими условиями на поверхности - с другой. Действительно, температура почвы полей контролировалась ее влажностью, что подтверждается сильной обратной зависимостью между этими показателями ( $r=-0,80 \ldots-0,72)$. Плотность сложения участка № 1 перед посевом рапса также достоверно определяла пространственную неоднородность температурного поля $(r=0,84)$.

Амплитуда сезонной динамики температуры 0-20 см слоя агрочерноземов определялась температурой приземных слоев атмоссреры. От мая к июню температура почвы на глубине 20 см постепенно повышалась с 4-5 до $13-16{ }^{\circ} \mathrm{C}$. В июльский период поверхность почвы в посевах масличных культур прогревалась до $29-30{ }^{\circ} \mathrm{C}$.
К концу августа агрочерноземы быстро охлаждались. В посевах рыжика и рапса отмечалось резкое снижение температуры почвы до $5-12{ }^{\circ} \mathrm{C}$ и отставание на $9-14^{\circ} \mathrm{C}$ от температуры воздуха.

Следует отметить, что характер агроценоза повлиял на ход сезонной динамики температуры 0-20 см слоя (табл. 2).Температурное поле пахотных почв перед посевом масличных культур определялось характером рельефа. Установлено, что склоновый участок № 2 в посевах рыжика отличался лучшей прогреваемостью. Далее от появления всходов до цветения масличных крестоцветных культур температура 0-20 см слоя агроценоза рапса и рыжика существенно не отличалась.

В июльский период интенсивный прирост надземной фитомассы рапса способствовал постепенному снижению температуры пахотного слоя на $1^{\circ} \mathrm{C}$. В фразу семяобразования и созревания рапса разница с агроценозом рыжика составила уже 5-8 ${ }^{\circ} \mathrm{C}$. Различный ход температуры 0-20 cм слоя агрочерноземов в период май-сентябрь отразился на среднестатистических величинах параметра. Установлено, что слой почвы 0-10 см прогревается на 2-3 ${ }^{\circ} \mathrm{C}$ больше, чем слой 10-20 см. При отсутствии достоверных отличий в температурном режиме почвы в посевах масличных культур определено, что 0-20 см слой почвы в агроценозе рыжика в среднем на $2{ }^{\circ} \mathrm{C}$ теплее, чем в агроценозе рапса. 

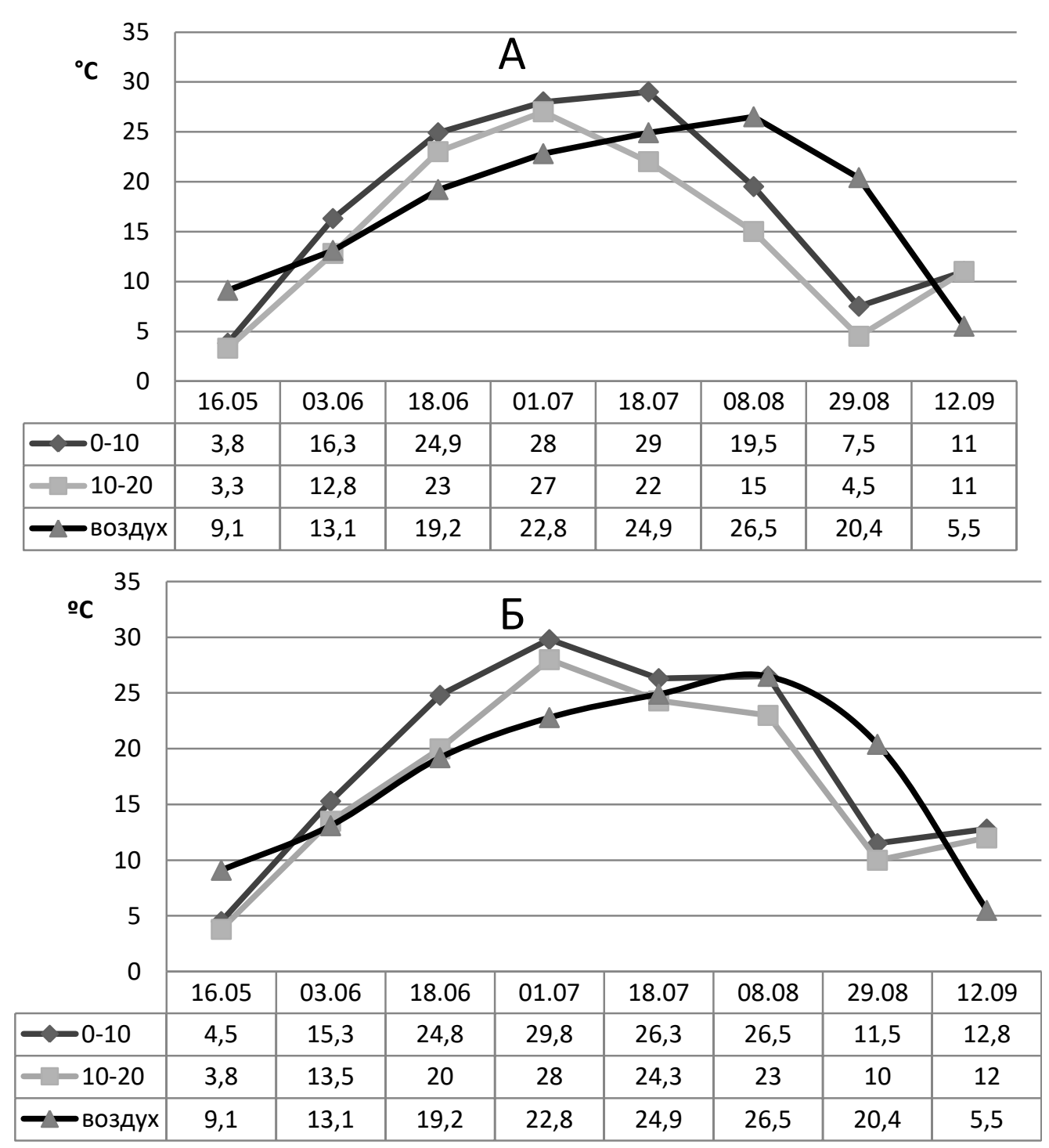

Средние показатели температурного режима 0-20 см слоя агрочерноземов в агроценозах рапса (А) и рыжика (Б), ${ }^{\circ} \mathrm{C}$

Таблица 2

\section{Статистические параметры температуры 0-20 см слоя агрочерноземов} в период май-сентябрь 2019 г., ${ }^{\circ} \mathrm{C}$

\begin{tabular}{|l|c|c|c|c|}
\hline \multirow{2}{*}{$\begin{array}{c}\text { Глубина, } \\
\text { см }\end{array}$} & $\mathrm{X} \pm \mathrm{Sx}$ & $\min$ & $\max$ & $\mathrm{C}_{\mathrm{v},} \%$ \\
\hline \multicolumn{5}{|c|}{ Рапс } \\
\hline $0-10$ & $17,5 \pm 7,9$ & 3,8 & 29,0 & 54 \\
\hline $10-20$ & $14,8 \pm 7,2$ & 3,3 & 27,0 & 59 \\
\hline \multicolumn{7}{|c|}{ Рыжик } \\
\hline $0-10$ & $18,9 \pm 7,6$ & 4,5 & 29,8 & 48 \\
\hline $10-20$ & $16,8 \pm 6,9$ & 3,8 & 28,0 & 49 \\
\hline$p_{0-10}$ & \multicolumn{5}{|c|}{0,762} \\
\hline$p_{10-20}$ & 0,644 \\
\hline
\end{tabular}


Заключение. Полученные результаты по термическому режиму пахотных горизонтов агрочерноземов в период вегетации масличных крестоцветных культур свидетельствуют о роли температуры приземного слоя почвы, рельефа и характера агроценоза в его формировании. Установлено, что ход сезонной динамики температуры 0-20 см слоя почвы определялся температурой приземных слоев атмосферы и достигал максимума в июльский период (29-30 $\left.{ }^{\circ} \mathrm{C}\right)$. При незначительной пространственной изменчивости температуры обрабатываемого слоя агрочерноземов ( $\mathrm{Cv}=10-19 \%$ ) склоновый участок поля № 2 агроценоза рыжика отличался лучшей прогреваемостью. Перед посевом культур температура склонового участка в среднем была выше на $2{ }^{\circ} \mathrm{C}(p=0,0001)$. Подобная закономерность сохранялась и в течение вегетации рыжика $(p=0,703)$.

\section{Литература}

1. Кречетов П.П., Черницова О.В. Экологогеографический анализ температурного режима почв Восточно-Европейской равнины и Предкавказья. - М.: Пеликан, 2007. $95 \mathrm{c}$.

2. Шеин Е.В., Болотов А.Г. [и др.]. Моделирование теплового режима почвы по амплитуде температуры приземного воздуха // Земледелие. - 2017. - № 7. - С. 26-28.

3. Димо В.Н. Тепловой режим почв СССР. М.: Колос, 1972. - $360 \mathrm{c}$.

4. Вередченко Ю.П. Агрофизическая характеристика почв центральной части Красноярского края. - М.: Изд-во АН СССР, 1961. $175 \mathrm{c}$.

5. Шугалей Л.С. Водный и питательный режим почв Красноярской лесостепи в связи с сезонной мерзлотой: автореф. дис. ... канд. биол. наук. - Красноярск, 1969. - 21 с.

6. Крупкин П.И. Черноземы Красноярского края. - Красноярск, 2002. - 331 с.

7. Беляев В.И., Бондарович А.А. [и др.]. Температурный режим воздуха и почвы по данным метеорологической и почвенногидрологической мониторинговой сети в Кулундинской равнине за вегетационные периоды 2013-2016 гг. // Вестник Алтайского государственного университета. - 2017. - № 3. - C. 30-37.

8. Шапорина Н.А., Чичулин А.В., Танасиенко A.A. Латеральная изменчивость агрофизических показателей и неоднородность гидротермического поля в почвенном покрове склоновых поверхностей Предсалаирья //Международный журнал прикладных и фундаментальных исследований. - 2016. № 2. - C. 1270-1275.

\section{Literatura}

1. Krechetov P.P., Chernicova O.V. Jekologogeograficheskij analiz temperaturnogo rezhima pochv Vostochno-Evropejskoj ravniny i Predkavkaz'ja. - M.: Pelikan, 2007. - 95 s.

2. Shein E.V., Bolotov A.G. [i dr.]. Modelirovanie teplovogo rezhima pochvy po amplitude temperatury prizemnogo vozduha II Zemledelie. - 2017. - № 7. - S. 26-28.

3. Dimo V.N. Teplovoj rezhim pochv SSSR. - M.: Kolos, 1972. - $360 \mathrm{~s}$.

4. Veredchenko Ju.P. Agrofizicheskaja harakteristika pochv central'noj chasti Krasnojarskogo kraja. - M.: Izd-vo AN SSSR, 1961. - 175 s.

5. Shugalej L.S. Vodnyj i pitatel'nyj rezhim pochv Krasnojarskoj lesostepi v svjazi s sezonnoj merzlotoj: avtoref. dis. ... kand. biol. nauk. Krasnojarsk, 1969. - $21 \mathrm{~s}$.

6. Krupkin P.I. Chernozemy Krasnojarskogo kraja. - Krasnojarsk, 2002. - $331 \mathrm{~s}$.

7. Beljaev V.I., Bondarovich A.A. [i $\mathrm{dr}$.$] .$ Temperaturnyj rezhim vozduha i pochvy po dannym meteorologicheskoj i pochvennogidrologicheskoj monitoringovoj seti $v$ Kulundinskoj ravnine za vegetacionnye periody 2013-2016 gg. // Vestnik Altajskogo gosudarstvennogo universiteta. - 2017. № 3. - S. 30-37.

8. Shaporina N.A., Chichulin A.V., Tanasienko A.A. Lateral'naja izmenchivost' agrofizicheskih pokazatelej i neodnorodnost' gidrotermicheskogo polja v pochvennom pokrove sklonovyh poverhnostej Predsalair'ja // Mezhdunarodnyj zhurnal prikladnyh i fundamental'nyh issledovanij. - 2016. - № 2. - S. 1270-1275. 